\title{
Apolipoprotein E \&4 Prevalence in Alzheimer's Disease Patients Varies across Global Populations: A Systematic Literature Review and Meta-Analysis
}

\author{
Sheila Crean ${ }^{\mathrm{a}}$ Alex Ward $^{\mathrm{a}}$ Catherine J. Mercaldi ${ }^{\mathrm{a}}$ Jenna M. Collins ${ }^{\mathrm{a}}$ \\ Michael N. Cook ${ }^{\text {b Nicole L. Baker }}{ }^{\text {b H. Michael Arrighi }}{ }^{\mathrm{c}}$ \\ a United BioSource Corporation, Lexington, Mass., bPfizer Inc., Collegeville, Pa., and \\ 'Janssen Alzheimer Immunotherapy Research and Development, LLC, South San Francisco, Calif., USA
}

\section{Key Words}

Alzheimer's disease $\cdot$ Apolipoprotein $\mathrm{E} \cdot$ Apolipoprotein $\mathrm{E}$ $\varepsilon 4$, prevalence in Alzheimer's disease

\begin{abstract}
Background: The $\varepsilon 4$ allele of apolipoprotein E (APOE) is associated with Alzheimer's disease (AD). However, attributable risk due to APOE4 varies by region and by race/ethnicity. Methods: A literature review and meta-analysis were conducted to estimate the prevalence of APOE4 by geographic area among AD patients. Results: Although estimates varied significantly by study design and case definition, AD patients recruited in Asian and southern European/Mediterranean communities seemed to have significantly lower E4 carrier status estimates (37 and 43\%) than those recruited in North America (58\%) or northern Europe (64\%; all: $p<0.05)$. Conclusions: APOE4 genotype frequency varies among AD patients in regional patterns similar to that of the general population. Study level differences may also contribute to the heterogeneity of published estimates of APOE4 in AD cases.
\end{abstract}

Copyright ๑ 2010 S. Karger AG, Basel

\section{KARGER}

Fax +41613061234 E-Mail karger@karger.ch www.karger.com

\section{Introduction}

Apolipoprotein E (APOE) is a cholesterol transport protein that exists as 3 alleles: $\varepsilon 2$ (E2), $\varepsilon 3$ (E3), and $\varepsilon 4$ (E4). As early as 1982, APOE4 was associated with lipid dysfunction, specifically type III hyperlipoproteinemia [1]. Ten years later, an excess of APOE4 allele relative to APOE3 was found in patients with memory disorders and late-onset familial and sporadic Alzheimer's disease (AD) [2-4]. APOE4 has been associated with about 65$75 \%$ of sporadic AD, but may be attributable to up to $20 \%$ of all dementias [5-7]. Furthermore, in a 1997 meta-analysis, the presence of an E4 allele decreased age at onset and increased the risk of disease as a gene dose, especially in patients with a disease onset between 40 and 60 years [8].

Because AD can manifest in the absence of an APOE4 genotype, 1 or 2 copies are neither necessary nor sufficient for pathology. Rather, the truncated APOE4 isoform is a susceptibility gene, increasing the likelihood of disease by compromising the glucose metabolism, inflammatory, and apoptotic responses of neuronal cells for decades before a second insult such as trauma or aging occurs [10]. APOE4 may then directly aggravate brain pathology by flooding cholesterol into these sites of nerve damage and complexing with amyloid- $\beta$ peptide into the

Sheila Crean, MPH

United BioSource Corporation

430 Bedford Street, Suite 300

Lexington, MA 02420 (USA)

Tel. +1 781960 0250, Fax +1 781761 0147, E-Mail sheila.crean@ unitedbiosource.com 
senile plaques, congophilic angiopathy, and neurofibrillary tangles of $\mathrm{AD}[9]$. AD is therefore the result of many genetic and environmental exposures that may or may not be prompted by an APOE4 allele load.

Estimating the AD risk attributed to APOE4 will be influenced by differences in APOE4 allele frequency within populations and the harm it poses relative to other factors. Indeed, while Corbo et al. [10] found that a frequency pattern of E3 $>$ E4 $>$ E2 was constant in each of the African, European, Asian, Oceanic, and Native American populations they compared, these allele frequencies varied along ethnic groups and across large routes of migration [11]. For example, Asian populations typically present with low APOE4 frequencies (7.1-24\%) relative to other populations. Across Europe, APOE4 frequency increases with latitude from the lowest frequencies in the world (Sardinia: 5.2\%) to one of the highest frequencies (Sami of Norway: 31.0\%) [2]. APOE4 status (defined as 1 or more E4 alleles) would be expected to vary among $\mathrm{AD}$ patients, first, as a simple function of the innate differences in allele frequency within human groups. Second, because AD is a multifactorial disease, other genetic and environmental exposures that differ by race, ethnicity, and culture will affect the association of APOE4 exposure and disease among peoples. Within communities, APOE4 carrier status may be established as a major predictor of $\mathrm{AD}$ in 1 group (Caucasians, for example), while being weak or inconsistent in others (African-Americans and Hispanics) [12-15]. Similarly, within populations of a similar descent, an effect size established between gene and phenotype in 1 country may not be significant in another $[13,16]$.

In the literature, APOE4 carrier status within an $\mathrm{AD}$ population will be confounded further by differences in AD case definition, ascertainment, and study design. Even when geographic area or ethnicity is held constant, sampling strategies such as case-control, cohort, and cross-sectional samples and recruitment settings such as clinical, community, and brain bank sources prove to be significant predictors of APOE4 frequency $[12,17]$.

We therefore conducted a literature review and metaanalysis to estimate the published mean prevalence of APOE 4 carriers (defined as the presence of 1 or 2 alleles) in $\mathrm{AD}$ patients by the host country of the clinic, the community, or the autopsy bank as a marker of both the underlying genetic and environmental components of the population seeking care. Aggregated estimates were further stratified and adjusted meta-analytically by potential confounders such as study design, case definition, and patient recruitment criteria.

\section{Methods}

The methods used for this review followed current best practices for conducting systematic reviews and meta-analyses of the literature $[18,19]$. Briefly, a systematic review collates all reproducible pieces of evidence that fit prespecified eligibility criteria in order to answer a specific, clearly stated clinical question. $\mathrm{Ob}$ jective scientific strategies are used to limit bias and random error in the acquisition, assembly, critical appraisal, and synthesis of the final eligible papers. Meta-analysis is the use of statistical methods to summarize the combined results of independent studies to provide a more precise estimate of risk or outcome. Meta-regression is a meta-analytic technique that can be used to investigate heterogeneity across studies by estimating the effect of treatment level or study level covariates on an outcome.

\section{Study Acquisition and Assembly}

MEDLINE (via PubMed), EMBASE, Current Contents, and the bibliographies of identified references were searched for English-language studies published within the past 24 years, for autopsies, community-based studies, and randomized clinical trials (RCTs). We conducted our search using a combination of text terms and Medical Subject Headings terms, combining strings specific for apolipoproteins, $\mathrm{AD}$, and focused terms for the 3 study types. Citations and abstracts of all studies identified in the search were downloaded and subjected to 2 levels of screening. In level 1, abstracts were searched for unambiguous evidence of protocol violations, such as insufficient number of subjects, wrong study design, an explicit exclusion of AD patients, or an abstract written in a language other than English. The full papers corresponding to the abstracts that passed level 1 were then retrieved and screened in detail. Rejection reasons at level 2 included paper contents in a foreign language; a non-AD population; no APOE outcomes of interest; a study design other than an RCT, a community-based, or an autopsy study, and fewer than 30 patients. Papers were rejected if the AD patients were not adults at the time of study entry or if results were mixed with other dementia groups. Papers were rejected if only a subset of AD cases was described, such as studies limited to patients with very-late-onset disease or autopsy studies restricted to a subtype of pathophysiology. Autopsy studies and community-based studies were limited to those published after December 2002. Finally, eligible articles were community-based observational studies; autopsy studies; phase II or III RCTs of donepezil, rivastigmine, galantamine, or memantine; written in English; and included APOE4 carrier proportions in adult $\mathrm{AD}$ patients. Papers that may describe the same $\mathrm{AD}$ population or tissue source (as evidenced by the same author names, institutions, or verbatim methodological language) were nested under a single 'parent' citation to avoid double counting of the same material. Using a data extraction form designed for this outcome, data were extracted independently by 2 investigators, and any differences were resolved by consensus before submitting the data elements to analysis.

\section{Study Dictionary}

Many authors defined AD cases based on National Institute of Neurological and Communicative Disorders and Stroke-Alzheimer's Disease and Related Disorders Association (NINCDSADRDA) criteria. For this analysis, 'possible AD' includes all cases that met the minimum requirements of $\mathrm{AD}$, i.e. NINCDS- 


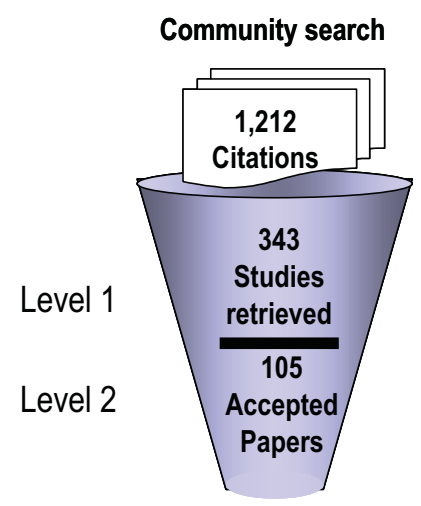

72 used in M-A

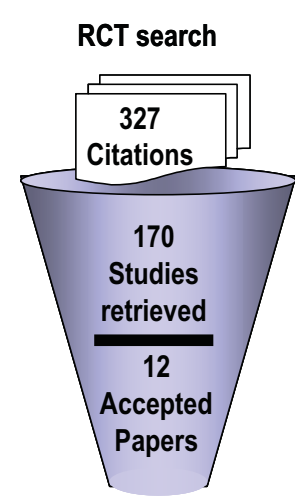

12 used in M-A

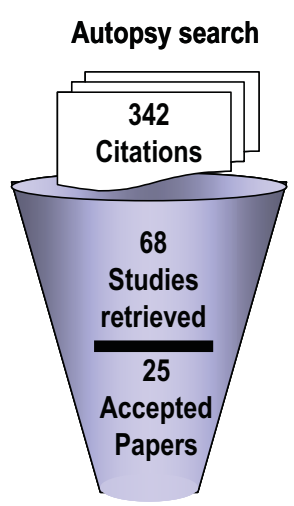

17 used in M-A

$\mathrm{M}-\mathrm{A}=$ Meta-analysis

Fig. 1. Study acquisition per search.

ADRDA-designated 'possible' as well as 'probable' and 'definite' AD cases. Diagnoses using NINCDS-ADRDA criteria with no further specification such as possible, probable, or definite were also included in this first category. 'Probable AD' included only those cases meeting the NINCDS-ADRDA criteria for 'probable' or 'definite' AD. The country in which the patients were recruited or the autopsy material was stored was used to discern geographic patterns. Geographic areas were defined as per www.nations online.org: Asia was defined as China, Iran, Japan, Korea, Russia, South Korea, Taiwan, and Turkey; the North American continent was defined as Canada, the United States, and Mexico; northern Europe was defined as Denmark, Finland, Ireland, the Netherlands, Norway, Sweden, and the United Kingdom; central Europe was defined as Austria, Belgium, Germany, Hungary, Poland, and Switzerland; southern European/Mediterranean countries were defined as Italy, Spain, and Tunisia, and 'other' was defined as Brazil, Colombia, or multiple countries.

\section{Statistical Analysis}

Study characteristics and subject level data were first summarized using SAS version 9.1 to calculate basic descriptive statistics (simple counts, means, and ranges) organized by region. The letter ' $k$ ' refers to the number of studies and the letter ' $n$ ' refers to the number of subjects. Restricted maximum likelihood varianceweighted random effects meta-analyses $[20,21]$ were next conducted on the APOE4 carrier proportions within each region of interest. Heterogeneity (between-study inconsistency) was investigated and measured using Cochran's $Q$ statistic and the $I^{2}$ statistic $[22,23]$. Cochran's Q, distributed as a $\chi^{2}$ statistic, estimates heterogeneity as the weighted sum of squared differences in effects across pooled studies. $\mathrm{I}^{2}$ estimates what percentage of interstudy variability is due to heterogeneity rather than to chance. When significant heterogeneity was present, we investigated variation using 2 methods. First, we stratified analyses by geographic location, study type, and AD definition. Next, we tested the effect of study design and age as predictors of regional APOE4 preva- lence within different $\mathrm{AD}$ definitions using random effects metaregression [23, 24]. Meta-regression functions in a way similar to that of multiple linear regression procedures, where the effect estimate is regressed on an intercept and, in the case of meta-regression, study level covariates. Terms were converted to binary categories and modeled simultaneously. Variables found to explain heterogeneity were then applied individually to APOE4 regional estimates to explain variance.

\section{Results}

\section{Study Level Results}

The literature search through MEDLINE (via PubMed), EMBASE, Current Contents, and manual bibliography checks yielded 342 citations for autopsy studies, 327 citations for RCTs, and 1,212 citations for communitybased studies. The attrition through level 1 and 2 screening is shown in figure 1 . Of the 142 publications that met protocol criteria, we accepted 101 studies described in 100 papers (online suppl. Appendix 1, www. karger.com/doi/10.1159/000321984) into the meta-analysis $(\mathrm{n}=24,197)$ as 'parent' publications and set aside 31 as repeat publications of the same patient pools. Of the 101 accepted studies, 17 were autopsy studies $(\mathrm{n}=1,549), 12$ were RCTs ( $\mathrm{n}=5,214)$, and 72 were community-based studies $(\mathrm{n}=17,434)$. Individual study results are represented in table 1 . Most studies recruited patients or material from Asian countries $(\mathrm{k}=25)$, North America $(\mathrm{k}=$ $23)$, or southern European/Mediterranean countries ( $\mathrm{k}=$ 22). Seven studies represented patients from South Amer- 
Table 1. Study characteristics

\begin{tabular}{|c|c|c|c|c|c|c|c|c|}
\hline & \multicolumn{2}{|c|}{ Overall } & \multicolumn{2}{|c|}{ Autopsy } & \multicolumn{2}{|c|}{ Community } & \multicolumn{2}{|c|}{$\mathrm{RCT}$} \\
\hline & $\mathrm{k}$ & $\mathrm{n}$ & $\mathrm{k}$ & $\mathrm{n}$ & $\mathrm{k}$ & $\mathrm{n}$ & $\mathrm{k}$ & $\mathrm{n}$ \\
\hline Total & 101 & 24,197 & 17 & 1,549 & 72 & 17,434 & 12 & 5,214 \\
\hline \multicolumn{9}{|l|}{ Geographic region } \\
\hline Asia & 25 & 5,695 & 1 & 100 & 22 & 5,297 & 2 & 298 \\
\hline North America & 23 & 5,809 & 9 & 912 & 11 & 3,223 & 3 & 1,674 \\
\hline Northern Europe & 17 & 5,930 & 3 & 333 & 11 & 4,725 & 3 & 872 \\
\hline Central Europe & 7 & 625 & 3 & 165 & 4 & 460 & - & - \\
\hline Southern Europe & 22 & 3,474 & 1 & 39 & 21 & 3,435 & - & - \\
\hline Other & 7 & 2,664 & - & - & 3 & 294 & 4 & 2,370 \\
\hline \multicolumn{4}{|c|}{$\begin{array}{l}\mathrm{k}=\text { Number of studies; } \mathrm{n}=\text { number of patients; Asia = China, } \\
\text { Iran, Japan, Korea, Russia, South Korea, Taiwan, and Turkey; } \\
\text { North America = Canada, the United States, and Mexico; Northern } \\
\text { Europe = Denmark, Sweden, the United Kingdom, Finland, Ire- }\end{array}$} & \multicolumn{5}{|c|}{$\begin{array}{l}\text { land, the Netherlands, and Norway; Central Europe = Austria, Bel- } \\
\text { gium, Germany, Hungary, Poland, and Switzerland; Southern } \\
\text { Europe/Mediterranean region = Italy, Spain, and Tunisia; Other = } \\
\text { Brazil, Colombia, international, and mixed. }\end{array}$} \\
\hline
\end{tabular}

ica $(\mathrm{k}=2)$ or were multinational efforts $(\mathrm{k}=5)$. Every region had at least 1 autopsy study or 4 community-based studies. However, no RCT in this review was conducted in central European or southern European/Mediterranean regions. Genotyping data stratified by patient level variables were rare. For example, gender-stratified APOE 4 carrier proportions were reported in only $9.9 \%$ of studies, and the ethnicity of the study population was described unambiguously in only $5 \%$. For age at AD diagnosis, not enough material was published for a subanalysis of author-defined early-onset and late-onset AD. Figure 2 presents individual study results grouped by type of study (autopsy, RCT, and community-based). The results are rank-ordered within each study type by the proportion of APOE4 carriers; the size of point estimate is proportional to the sample size of the study, and each estimate is given with an associated $95 \%$ confidence interval (CI). This figure shows a substantial variation within each of the study designs and that individual point estimates overlap considerably across study designs.

\section{Prevalence of APOE4 Carrier Proportions across \\ Geographic Regions}

The country that hosted the study or provided autopsy material was used as a marker for the genetic and environmental exposures of the AD patients seeking care locally. Estimates for the proportion of APOE4 carriers were therefore estimated for 5 regions: Asia, North America, northern Europe, central Europe, and southern Europe/Mediterranean region, as seen in figure 3. When region-based studies were compared meta-analytically,

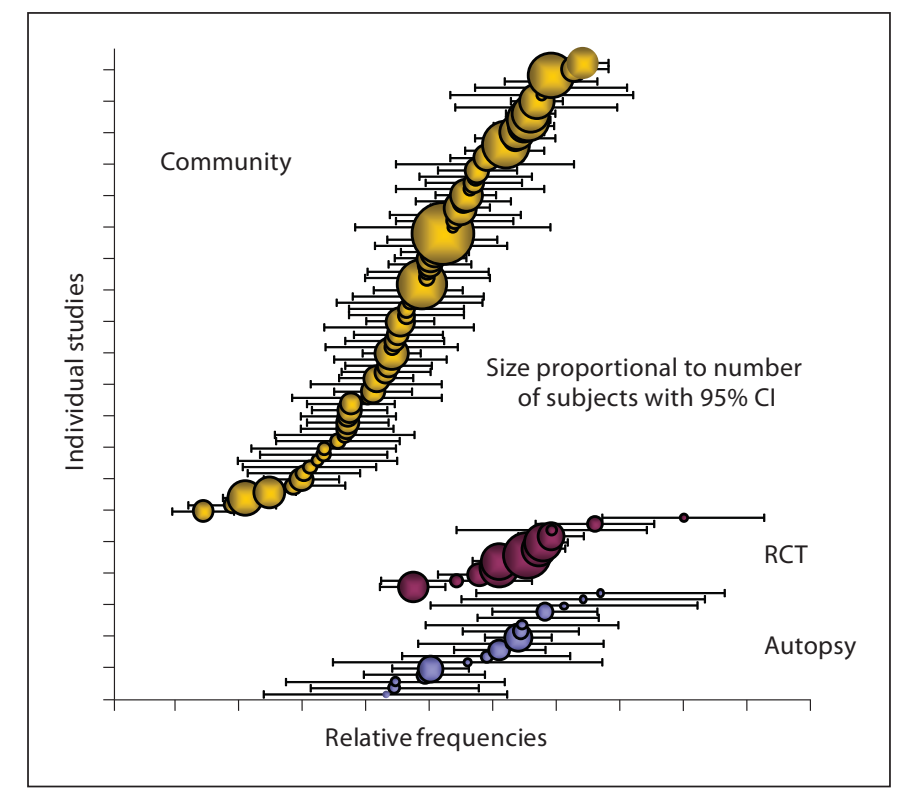

Fig. 2. APOE 4 carrier frequency among AD patients: individual study results by study type.

the APOE4 carrier proportion pooled from AD patients recruited to Asian studies was $38.90 \%$ (95\% CI 33.4344.38); the proportion from southern European/Mediterranean countries was $43.11 \%$ (95\% CI 40.27-45.95); the proportion from central Europe was 53.69\% (95\% CI 45.66-61.73); the proportion from North America was $59.06 \%$ (95\% CI 54.98-63.15), and the proportion from 
Fig. 3. Meta-analytic estimates and heterogeneity measures of the prevalence of APOE carriers by geographic region.

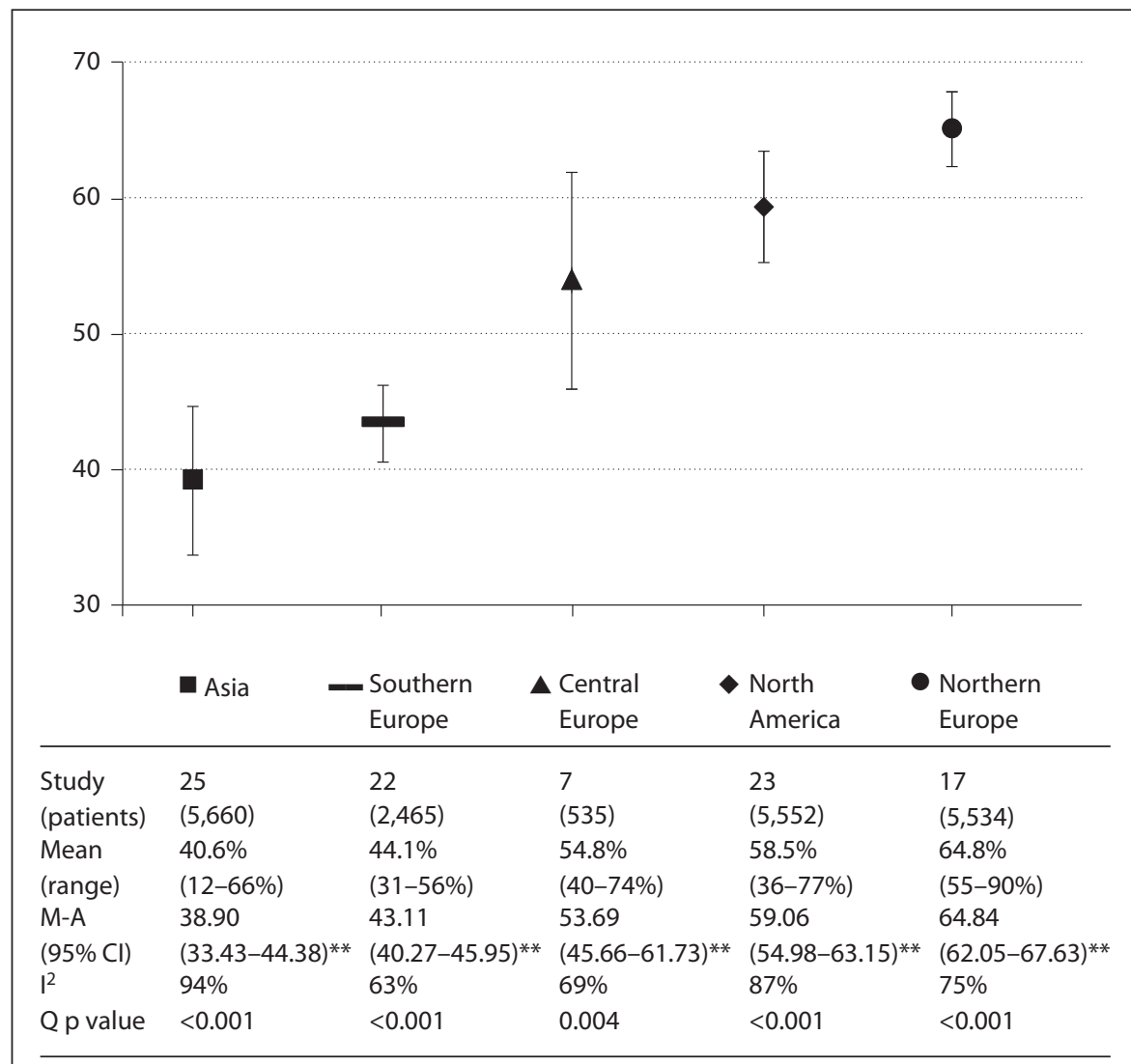

$I^{2}=I^{2}$ statistic of interstudy variability; $Q=$ Cochran's $Q$ statistic of heterogeneity; $M-A=$ meta-analysis. The asterisks indicate highly significant heterogeneity if $\mathrm{p}<0.01$. northern Europe was 64.84\% (95\% CI 62.05-67.63). Estimates pooled by region displayed significantly high heterogeneity ( $p \leq 0.004$ ), with most of this variance due to inconsistent study results rather than random chance $\left(\mathrm{I}^{2} \geq 63 \%\right)$. Indeed, the estimates derived from studies in Asia and North America were particularly disparate $\left(\mathrm{I}^{2} \geq 85 \%\right)$. In spite of the variance observed, the estimate pooled from Asian studies tended to be lower than that of North America and northern Europe.

\section{APOE4 Carrier Proportions across Study Designs}

Estimates for regional genotyping may be potentially confounded by differences in $\mathrm{AD}$ case definitions and sampling. As seen in figure 4, meta-analyzed estimates of APOE 4 carrier prevalence rates were $47.21 \%$ (95\% CI 43.96-50.47) for community-based studies, 58.68\% (95\% CI 54.14-63.22) for autopsy studies, and 63.47\% (95\% CI 58.34-68.61) for RCTs. All 3 estimates were determined to display substantial heterogeneity by Cochran's Q sta- tistic ( $\mathrm{p} \leq 0.001)$. Further, the bulk of this variance seems to be due to true differences between studies and not due to random chance $\left(\mathrm{I}^{2} \geq 61 \%\right)$. By this statistic, almost all of the variance (95\%) calculated from community-based studies seems due to heterogeneity, although it is noteworthy that despite this heterogeneity, community-based studies consistently reported lower APOE 4 carrier prevalence than either RCTs or autopsy studies.

\section{APOE4 Carrier Proportions across Case Definitions}

The influence of $\mathrm{AD}$ case definition was next explored for associations with APOE carrier proportions. As seen in figure 5 , when studies were stratified by cases reported to be at least 'possible' $\mathrm{AD}$ and those reported to be at least 'probable' AD, meta-analyzed estimates of APOE4 carrier prevalence rates were $48.50 \%$ (95\% CI 43.72-53.28) and $52.29 \%$ (95\% CI 49.25-55.33), respectively. As seen above regarding study design, both estimates were significantly heterogeneous $(\mathrm{p} \leq 0.001)$. By $\mathrm{I}^{2}$ statistical 
Fig. 4. Meta-analytic estimates and heterogeneity measures of the prevalence of APOE carriers by study design.

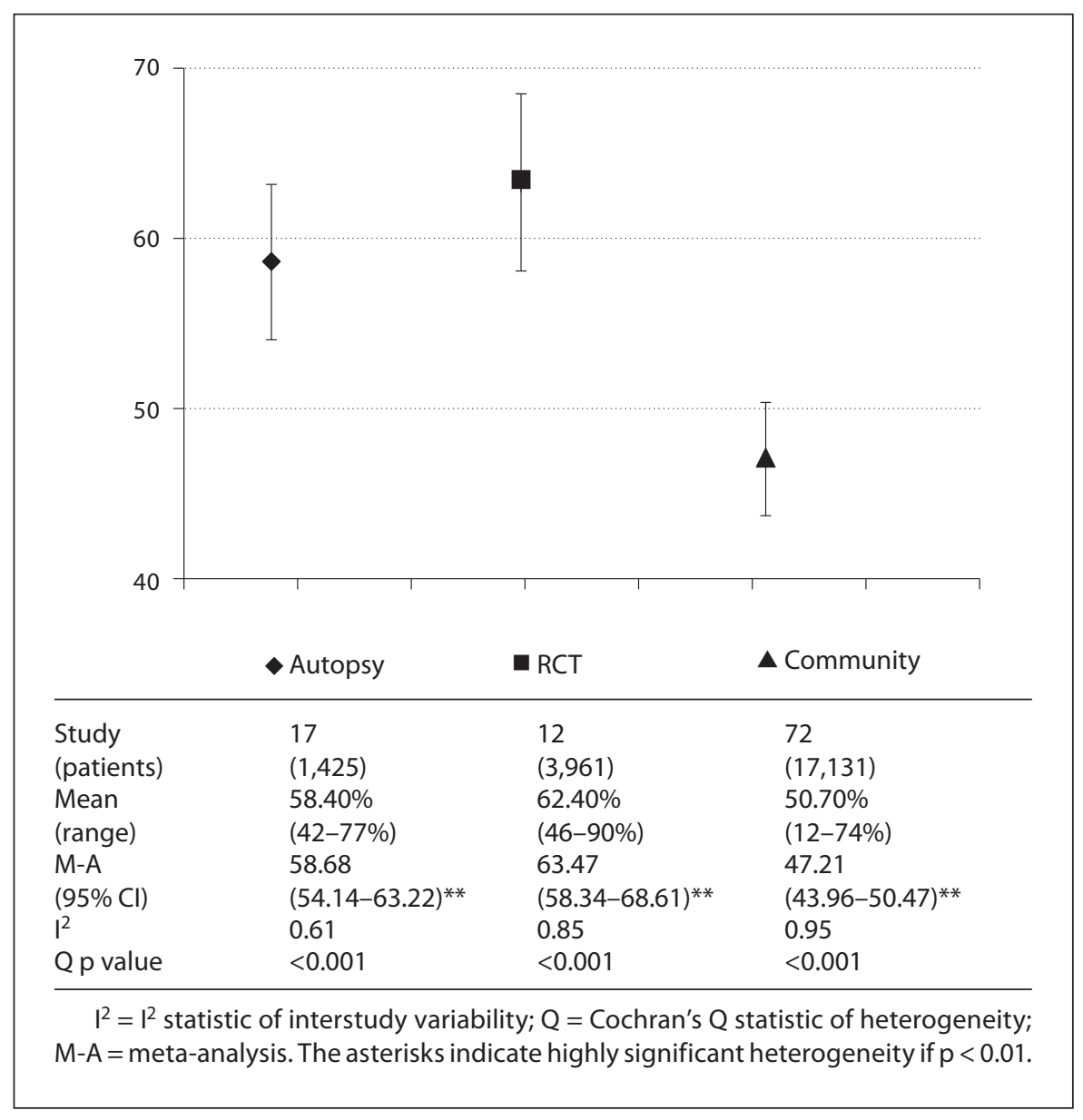

testing, almost all the variance ( $\geq 92 \%$ ) for both estimates seems due to heterogeneity and not random sampling. The difference between estimates stratified by case definition did not achieve statistical significance.

\section{APOE4 Carrier Proportions in Community-Based}

Studies Adjusted for Host Country, Study Design, and Case Definition

Because differences in study designs or case definitions may drive differences in APOE proportions, estimates for regional genotyping may be potentially confounded by these variables. A restricted analysis was therefore performed to reduce the influence of these confounding factors on regional estimates for the 72 community-based studies in this review. As seen in figure 6, regional APOE4 estimates for this subset of studies again proved inconsistent (Cochran's $\mathrm{Q}, \mathrm{p} \leq 0.001$ ), with most of the variance due to study result heterogeneity $\left(\mathrm{I}^{2} \geq\right.$ 65\%). Likewise, the aggregated estimate derived from
Asian community-based studies, 37.08\% (95\% CI 31.3442.82), was substantially lower than estimates associated with North American and northern European community-based studies [57.76\% (95\% CI 51.43-64.09) and 64.06\% (95\% CI 60.44-67.69), respectively].

Community-based studies were next organized into 2 groups: those studies in which 'possible' AD cases were eligible and those studies that restricted eligibility to 'probable' and 'definite' AD cases only. For each region, APOE4 carrier estimates from 'possible' AD studies were the same as or lower than those from 'probable' AD studies, but this difference did not achieve statistical significance within any region. Significantly high heterogeneity remained in estimates pooled for 'possible' AD patients in community-based studies conducted in Asia, North America, and southern European/Mediterranean countries and for 'probable' AD patients in Asia, northern Europe, central Europe, and southern European/Mediterranean countries. Heterogeneity was significant, but re- 
Fig. 5. Meta-analytic estimates and heterogeneity measures of the prevalence of APOE carriers by case definition.

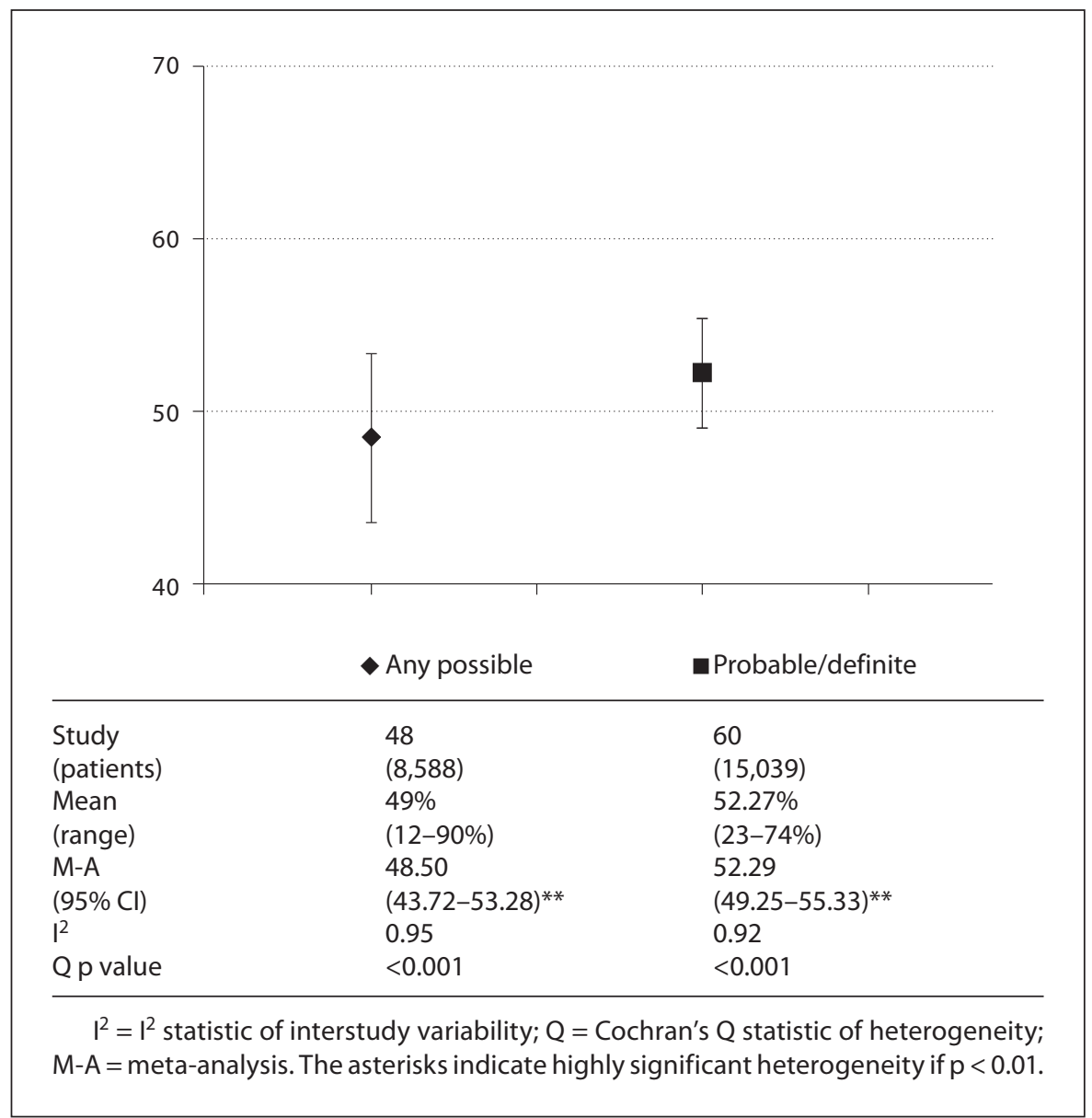

duced somewhat $(\mathrm{p}<0.8)$, for 'possible' AD patients recruited in northern Europe and for 'probable' AD patients in North America. A single estimate, for 'possible' $\mathrm{AD}$ cases recruited from communities in central Europe, seems to draw on studies with consistent results (Cochran's $\left.Q, p=0.398 ; I^{2}=0 \%\right)$. Asian and southern European/Mediterranean APOE4 carrier proportions stratified by either case definition seemed statistically significant.

\section{Meta-Regression Model of Covariates to APOE4}

Carrier Proportions across Geographic Regions

Meta-regression was next conducted to investigate potential reasons for variation among results within a given region and definition of $\mathrm{AD}$ for all studies in this review. The intercept term represents the meta-analyzed proportion of the referent group: AD patients in communitybased studies of either cohort or cross-sectional design and with a mean age at study onset of $>73$ years (the 25 th percentile of all studies). Using binary coding, we tested the effect of autopsy/RCT settings versus the referent community-based design, then case-control study design versus cohort/cross-sectional subdesign, and finally mean study age in the lowest quartile ( $<73$ years) versus study populations with higher mean age. In table 2 , regions with sufficient variation were tested. The estimate for a covariate indicates the effect of the specific covariate when added to the intercept. For example, the proportion of North American patients diagnosed as having 'possible' AD with 1 or 2 APOE4 alleles would be $57 \%$ for autopsy studies of non-case-control design and with a mean age of $>73$ years [0.46 (intercept) +0.11 (autopsy studies) $=0.57]$. Upon meta-regression, none of these variables adequately explained the heterogeneity of the regional results, although there was some evidence of higher prevalence of E4 carriers in case-control studies versus other designs among northern European studies with 'probable' AD definitions (coefficient $=0.13,95 \% \mathrm{CI}=0.02-0.24$ ). However, the number of studies was small $(\mathrm{k}=5 ; \mathrm{n}=2,595)$. 
Fig. 6. Meta-analysis of E4 carrier status in community-based studies by geographic region and case definition.

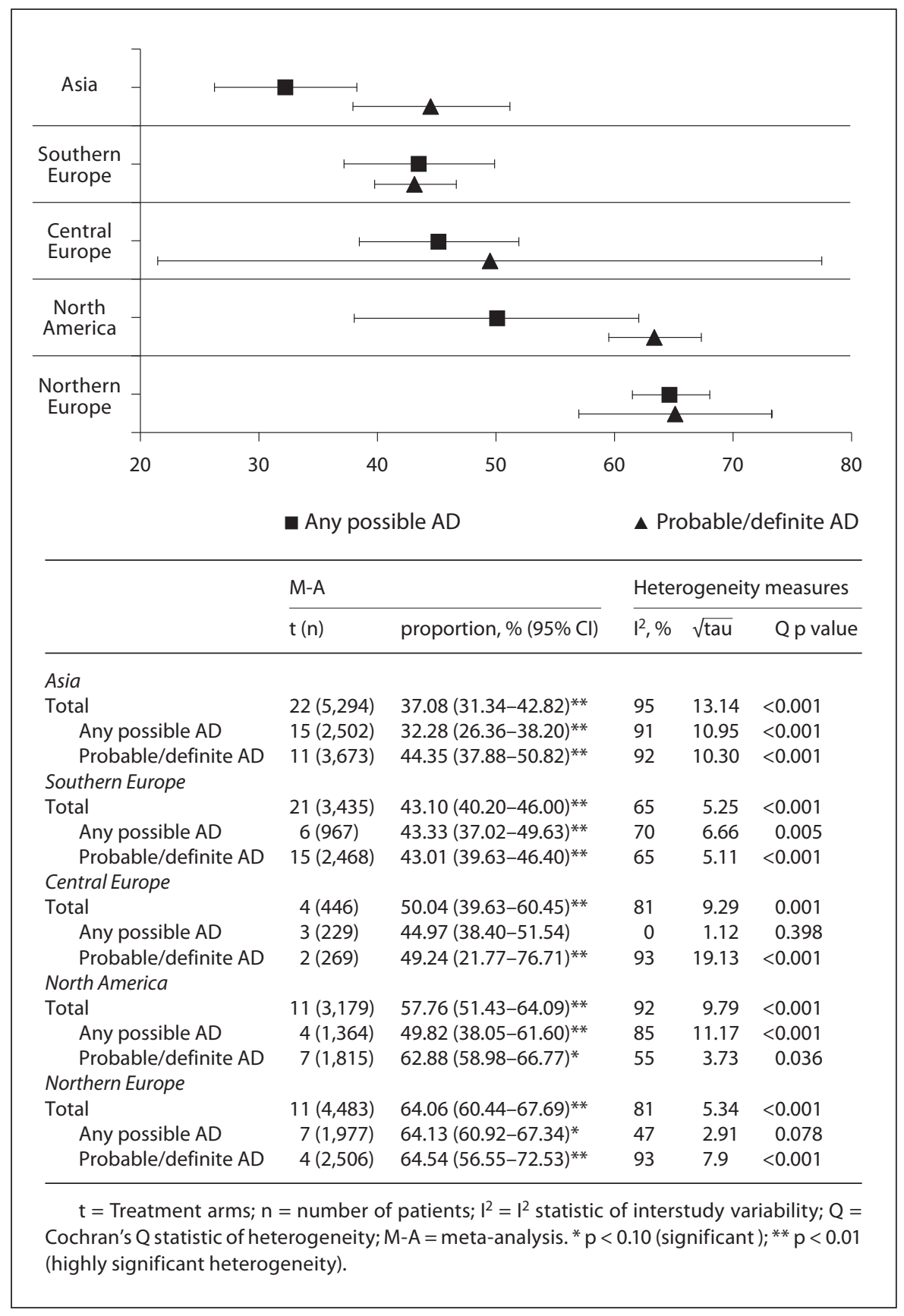

\section{Discussion}

In this literature review and meta-analysis, we estimated APOE4 prevalence in AD patients by the host country of the study in an attempt to account for the combination of genetic and environmental exposures of the residents. When stratified by country (presumptively a geopolitical construct of race and culture), differences were detected in APOE4 carrier estimates. Although all APOE 4 carrier estimates were tested as very heterogeneous, the estimate for $\mathrm{AD}$ patients recruited from Asia seems significantly lower than that of North America and northern Europe. This pattern is consistent with the published general population studies compared by Corbo et 
Table 2. Meta-regression results

\begin{tabular}{|c|c|}
\hline & E4/any \\
\hline \multicolumn{2}{|l|}{ Asia } \\
\hline Possible AD, $t$ (n) & $15(2,502)$ \\
\hline Intercept & $0.20(0.05$ to 0.35$)$ \\
\hline Case-control studies & $0.14(-0.03$ to 0.30$)$ \\
\hline Mean age in lowest quartile ${ }^{\mathrm{a}}$ & $0.08(-0.14$ to 0.31$)$ \\
\hline \multicolumn{2}{|l|}{ North America } \\
\hline Possible AD, $t$ (n) & $10(1,805)$ \\
\hline Intercept & $0.46(0.34$ to 0.57$)$ \\
\hline Autopsy studies & $0.11(-0.05$ to 0.27$)$ \\
\hline Case-control studies & $0.20(-0.10$ to 0.49$)$ \\
\hline Mean age in lowest quartile $\mathrm{e}^{\mathrm{a}}$ & $0.21(-0.06$ to 0.47$)$ \\
\hline Probable $\mathrm{AD}, \mathrm{t}(\mathrm{n})$ & $15(3,924)$ \\
\hline Intercept & $0.61(0.53$ to 0.68$)$ \\
\hline Autopsy studies & $-0.02(-0.12$ to 0.08$)$ \\
\hline RCT studies & $0.03(-0.09$ to 0.15$)$ \\
\hline Case-control studies & $0.04(-0.07$ to 0.15$)$ \\
\hline Mean age in lowest quartile $\mathrm{e}^{\mathrm{a}}$ & $0.04(-0.12$ to 0.20$)$ \\
\hline \multicolumn{2}{|l|}{ Northern Europe } \\
\hline Possible AD, $t$ (n) & $12(2,939)$ \\
\hline Intercept & $0.63(0.55$ to 0.71$)$ \\
\hline Autopsy studies & $-0.02(-0.16$ to 0.12$)$ \\
\hline RCT studies & $0.07(-0.07$ to 0.20$)$ \\
\hline Case-control studies & $0.00(-0.11$ to 0.12$)$ \\
\hline Mean age in lowest quartile $\mathrm{e}^{\mathrm{a}}$ & $0.03(-0.09$ to 0.15$)$ \\
\hline Probable AD, t (n) & $5(2,595)$ \\
\hline Intercept & $0.58(0.50$ to 0.66$)$ \\
\hline Autopsy studies & $0.08(-0.08$ to 0.25$)$ \\
\hline Case-control studies & $0.13(0.02$ to 0.24$)$ \\
\hline \multicolumn{2}{|c|}{ Southern Europe/Mediterranean region } \\
\hline Possible AD, $t(n)$ & $6(967)$ \\
\hline Intercept & $0.50(0.36$ to 0.63$)$ \\
\hline Case-control studies & $-0.09(-0.26$ to 0.08$)$ \\
\hline Mean age in lowest quartile & $-0.01(-0.21$ to 0.19$)$ \\
\hline Probable AD, t (n) & $16(2,498)$ \\
\hline Intercept & $0.45(0.38$ to 0.52$)$ \\
\hline Autopsy studies & $-0.02(-0.24$ to 0.20$)$ \\
\hline Case-control studies & $0.00(-0.09$ to 0.08$)$ \\
\hline Mean age in lowest quartile ${ }^{a}$ & $-0.04(-0.12$ to 0.03$)$ \\
\hline \multicolumn{2}{|c|}{$\begin{array}{l}t=\text { Treatment arms; } \mathrm{n}=\text { number of patients. Figures are means } \\
\text { with } 95 \% \text { CIs in parentheses unless indicated otherwise. } \\
\quad{ }^{a}<73 \text { years. }\end{array}$} \\
\hline
\end{tabular}

al. [2]. They found that APOE3 and APOE4 frequencies are inversely correlated and distributed across Europe in a pattern across a north-to-south cline. That is, people along the Mediterranean basin show the lowest APOE4 frequencies in the world (0.052-0.091), while Nordic people exhibit the highest $(0.163-0.310)$.
We hypothesized that differences in recruitment techniques, sampling methods, and case definitions may be expected to confound published E4 homozygote and heterozygote $\mathrm{AD}$ case prevalence estimates stratified by study region. Indeed, when we compared these study design differences, we found that observational community-based studies had a lower estimate of E4 carriers than autopsy studies or RCTs, although the results across all study designs were also statistically very heterogeneous. Selection bias and misclassification error are likely to influence these differences. First, AD patients recruited for an RCT are more likely to be younger, white, better educated, and without the serious comorbidities (e.g. diabetes, hypertension, high cholesterol) that would contribute to the onset or the worsening of dementia than a community-based population screened for $\mathrm{AD}$. Thus, the proportions of AD cases attributable to APOE4 may be overrepresented in an RCT group compared to populations recruited from the community or from a brain bank. Second, patients recruited to an RCT are likely to be required to meet a strict case definition and are often limited to the NINCDS-ADRDA criteria of 'probable' AD or its equivalent, with additional eligibility criteria, compared to cases identified in community-based studies that include 'possible' and 'probable' AD. The clinical diagnostic accuracy of $\mathrm{AD}$ has been reported to be as low as $65 \%$; thus, some AD cases recruited for studies may actually be misclassified cases of dementia due to vascular disease, Lewy body disease, and Pick's disease [24]. A 2001 literature review suggests that the additional neuroimaging evidence to meet the NINCDS-ADRDA criteria for 'probable' AD would improve the specificity of case definitions in 'probable' AD patients compared to 'possible' AD cases from 48 to $70 \%$ [25]. In this review, those studies that required $\mathrm{AD}$ cases to be objectively proven with neuroimaging (the NINCDS-ADRDA criteria for 'probable') had higher E4 carrier proportions than 'possible' cases that were eligible based on neuropsychological testing alone. All 12 RCT studies reviewed here required a diagnosis of 'probable' AD, and, in marked contrast, one third of community-based studies allowed 'possible' AD. Furthermore, in the largest population-based studies, case definition was based on a single abbreviated interview outside of the clinic. Therefore, different proportions of 'probable' AD cases may be driving the higher E4 estimate derived from RCTs when compared to communitybased studies.

$\mathrm{AD}$ is a heterogeneous disease; familial $\mathrm{AD}$, sporadic $\mathrm{AD}$, early-onset $\mathrm{AD}$, and late-onset $\mathrm{AD}$ present with distinct clinical and histological profiles, and as a result are

Crean/Ward/Mercaldi/Collins/Cook/ Baker/Arrighi 
often stratified by subtypes of etiology and prognosis [24, 26]. Such categories were insufficiently reported in the published literature, and this may explain, in part, the substantial amount of cross-study heterogeneity demonstrated across every analysis. When differences in study design and diagnostic uncertainty were tested upon meta-regression, no factor tested sufficiently predicted the variance within regional estimates.

Substantial heterogeneity has implications for these findings, future research, and targeted drug therapies. Because of the potential confounding due to case definition and sampling, differences in estimates across studies and regions may or may not reflect true differences in the underlying genotype frequencies. In addition, any true association of APOE4 with the risk of AD for any given people may be obscured due to this heterogeneity despite the quality and internal consistency of any single study. Projections from the literature of who is at risk for APOE4-attributable AD and who would benefit from APOE4-targeted therapies should therefore be approached with caution.

Our study shares the same limitations of any review of published literature. Community and autopsy studies had to be published after December 2002, and study populations were held to 30 patients or more. Genotyping results stratified by race or ethnicity were rarely reported even for an allelic marker known to be associated with such demographics. Also sparse were any attempts to describe genotyping by plaque or tangle predominance categories, disease severity, AD etiology, or likelihood of correct diagnosis. Further stratification into demographic or disease subgroups would undoubtedly reduce the heterogeneity of regional estimates, but was not possible from this data source. Our estimates, however, are based on a key term search of RCT, autopsy, and communitybased studies in AD patients, with no bias toward APOE genotyping results. Papers were extensively and conservatively examined for any indication that the same population may be twice described. Estimates, therefore, are derived from fair and independent samplings of the literature. Further, we have identified and tested by metaanalysis new possible confounders of case definition, study design, and recruitment. The APOE4 frequencies organized here represent the best estimates across human groups with $\mathrm{AD}$ assembled from the literature and suggest new possible confounders to consider in future work.

In summary, mean estimates of APOE 4 carrier prevalence in $\mathrm{AD}$ cases varied significantly when organized by the country hosting the study. Specifically, this literature review reveals that study design, case definition, and patient recruitment may influence the wide range of published estimates of APOE4 within these local AD populations, but no single variable sufficiently explained region variance when meta-analyzed.

\section{Acknowledgments}

The authors would like to acknowledge the thoughtful comments and suggestions throughout this project from Dr. Nicole Schupf, Taub Institute, Columbia University. This study was sponsored by Elan Pharmaceuticals, Inc. (Janssen Alzheimer Immunotherapy acquired the Alzheimer Immunotherapy Program from Elan in September 2009) and Wyeth (which was acquired by Pfizer in October 2009).

\section{References}

1 Rall SC Jr, Weisgraber KH, Mahley RW: Human apolipoprotein E. The complete amino acid sequence. J Biol Chem 1982;257:41714178.

2 Saunders AM, Strittmatter WJ, Schmechel D, George-Hyslop PH, Pericak-Vance MA, Joo SH, Rosi BL, Gusella JF, Crapper-MacLachlan DR, Alberts MJ, et al: Association of apolipoprotein $\mathrm{E}$ allele epsilon 4 with lateonset familial and sporadic Alzheimer's disease. Neurology 1993;43:1467-1472.

- 3 Corder EH, Saunders AM, Strittmatter WJ, Schmechel DE, Gaskell PC, Small GW, Roses AD, Haines JL, Pericak-Vance MA: Gene dose of apolipoprotein E type 4 allele and the risk of Alzheimer's disease in late onset families. Science 1993;261:921-923.
Roses AD: On the discovery of the genetic association of apolipoprotein E genotypes and common late-onset Alzheimer disease. J Alzheimers Dis 2006;9:361-366.

5 Ponomareva NV, Korovaitseva GI, Rogaev EI: EEG alterations in non-demented individuals related to apolipoprotein E genotype and to risk of Alzheimer disease. Neurobiol Aging 2008;29:819-827.

6 He J, Gui JH, Zhang YH, Yu WZ, Chou DH, $\mathrm{Xu}$ JT, Song YB: Relationship between apolipoprotein $\mathrm{E}$ gene and the risk for onset of Alzheimer disease in aged adults in Urumqi. Chin J Clin Rehabil 2005;9:207-209.
Sleegers K, Roks G, Theuns J, Aulchenko YS, Rademakers R, Cruts M, van Gool WA, van Broeckhoven C, Heutink P, Oostra BA, van Swieten JC, van Duijn CM: Familial clustering and genetic risk for dementia in a genetically isolated Dutch population. Brain 2004; 127:1641-1649.

8 Davidson Y, Gibbons L, Pritchard A, Hardicre J, Wren J, Stopford C, Julien C, Thompson J, Payton A, Pickering-Brown SM, Pendleton N, Horan MA, Burns A, Purandare N, Lendon CL, Neary D, Snowden JS, Mann DM: Apolipoprotein E epsilon4 allele frequency and age at onset of Alzheimer's disease. Dement Geriatr Cogn Disord 2007;23: 60-66. 
-9 Strittmatter WJ, Saunders AM, Schmechel D, Pericak-Vance M, Enghild J, Salvesen GS, Roses AD: Apolipoprotein E: high-avidity binding to beta-amyloid and increased frequency of type 4 allele in late-onset familial Alzheimer disease. Proc Natl Acad Sci USA 1993;90:1977-1981.

- 10 Corbo RM, Scacchi R: Apolipoprotein E (APOE) allele distribution in the world. Is $\mathrm{APOE}^{*} 4$ a 'thrifty' allele? Ann Hum Genet 1999;63:301-310.

-11 Tang MX, Maestre G, Tsai WY, Liu XH, Feng L, Chung WY, Chun M, Schofield P, Stern Y, Tycko B, Mayeux R: Relative risk of Alzheimer disease and age-at-onset distributions, based on APOE genotypes among elderly African Americans, Caucasians, and Hispanics in New York City. Am J Hum Genet 1996;58: 574-584.

-12 Farrer LA, Cupples LA, Haines JL, Hyman B, Kukull WA, Mayeux R, Myers RH, PericakVance MA, Risch N, van Duijn CM: Effects of age, sex, and ethnicity on the association between apolipoprotein $\mathrm{E}$ genotype and Alzheimer disease. A meta-analysis. APOE and Alzheimer Disease Meta Analysis Consortium. JAMA 1997;278:1349-1356.

-13 Murrell JR, Price B, Lane KA, Baiyewu O, Gureje O, Ogunniyi A, Unverzagt FW, Smith-Gamble V, Gao S, Hendrie HC, Hall KS: Association of apolipoprotein E genotype and Alzheimer disease in African Americans. Arch Neurol 2006;63:431-434.
14 Tang MX, Stern Y, Marder K, Bell K, Gurland B, Lantigua R, Andrews H, Feng L, Tycko B, Mayeux R: The APOE-epsilon4 allele and the risk of Alzheimer disease among African Americans, whites, and Hispanics. JAMA 1998;279:751-755.

-15 Graff-Radford NR, Green RC, Go RC, Hutton ML, Edeki T, Bachman D, Adamson JL, Griffith P, Willis FB, Williams M, Hipps Y, Haines JL, Cupples LA, Farrer LA: Association between apolipoprotein E genotype and Alzheimer disease in African American subjects. Arch Neurol 2002;59:594-600.

16 Ogunniyi A, Baiyewu O, Gureje O, Hall KS Unverzagt F, Siu SH, Gao S, Farlow M, Oluwole OS, Komolafe O, Hendrie HC: Epidemiology of dementia in Nigeria: results from the Indianapolis-Ibadan study. Eur J Neurol 2000; 7:485-490.

17 Tsuang D, Kukull W, Sheppard L, Barnhart RL, Peskind E, Edland SD, Schellenberg G, Raskind M, Larson EB: Impact of sample selection on APOE epsilon 4 allele frequency: a comparison of two Alzheimer's disease samples. J Am Geriatr Soc 1996;44:704-707.

18 Alderson P, Green S, Higgins JPT (eds) Cochrane Collaboration Handbook 4.2.1 [updated December 2003]. The Cochrane Library. Chichester, Wiley, 2004.

19 Cook DJ, Mulrow CD, Haynes RB: Systematic reviews: synthesis of best evidence for clinical decisions. Ann Intern Med 1997;126 $376-380$
20 Hedges L, Olkin I: Statistical Methods for Meta-Analysis. Orlando, Academic Press, 1985, pp 230-257.

21 DerSimonian R, Laird N: Meta-analysis in clinical trials. Control Clin Trials 1986;7: 177-188.

22 Higgins JP, Thompson SG, Deeks JJ, Altman DG: Measuring inconsistency in meta-analyses. BMJ 2003;327:557-560.

-23 Berkey CS, Hoaglin DC, Mosteller F, Colditz GA: A random-effects regression model for meta-analysis. Stat Med 1995;14:395-411.

24 Jellinger KA: Con: Can neuropathology really confirm the exact diagnosis? Alzheimers Res Ther 2010;2:11.

25 Knopman DS, DeKosky ST, Cummings JL, Chui H, Corey-Bloom J, Relkin N, Small GW, Miller B, Stevens JC: Practice parameter: diagnosis of dementia (an evidence-based review). Report of the Quality Standards Subcommittee of the American Academy of Neurology. Neurology 2001;56:1143-1153.

$>26$ Jack CR Jr, Knopman DS, Jagust WJ, Shaw LM, Aisen PS, Weiner MW, Petersen RC, Trojanowski JQ: Hypothetical model of dynamic biomarkers of the Alzheimer's pathological cascade. Lancet Neurol 2010;9:119128. 